\title{
Cultural Baggage: Autobiographical Writings by Wanda Rutkiewicz and Arlene Blum
}

\section{Abstract}

The article aims to compare and contrast two autobiographical stories, Wanda Rutkiewicz's $\mathrm{Na}$ jednej linie [On One Rope] (1986), co-authored with Ewa Matuszewska, and Arlene Blum's Breaking Trail, published in 2005. Unfolding the experiences of the female mountaineers from two different cultural backgrounds, it analyzes how their mutual encounters are narrated by Blum, the American icon of climbing, and by Rutkiewicz, the first Polish high-altitude mountaineer to scale Mount Everest. The article also examines the personal narratives by applying to the text analysis Edward Hall's division into high-context and low-context cultures and Geert Hofstede's cultural individualism-collectivism dimension.

Keywords: autobiography, Blum, Hall, Hofstede, mountain, Rutkiewicz

\section{Introduction}

A computer engineer by profession, Wanda Rutkiewicz (1943-1992) made history when she became the first Polish high-altitude mountaineer and the first European woman to scale Mount Everest. Thus, it is not surprising that upon her return from the international expedition to the top of the world, Aleksander Lwow divided Polish alpinism into three categories: "1. men's alpinism, 2. women's alpinism, 3. Wanda Rutkiewicz" (McDonald 66), which stresses her outstanding achievements as well as her individual style of climbing that some have severely criticized. Despite male alpinists' disbelief that women could climb McKinley, in 1970, scientist and mountaineer Arlene Blum (b. 1945) co-led the Denali Damsels group, the first team of women that successfully reached the highest peak in North America. In addition, partially inspired by Rutkiewicz, whom she 
had met on the slope of Noshaq, Blum led the 1978 American Women's Himalayan Expedition, which succeeded in summiting Annapurna I, "a difficult mountain to see up close, much less climb" (Rak 109). The influential figures in women's mountaineering, both Himalayan climbers have written intriguing personal narratives of their on-the-edge lives. Living in a satellite country of the Soviet Union, Rutkiewicz co-authored Na jednej linie (On One Rope) with Ewa Matuszewska and published the book in $1986,[1]$ whereas Blum, working mainly in the 20th-century superpower, released Breaking Trail in 2005. The article aims to compare and contrast the two stories that unfold the experiences of the female mountaineers from two different cultural backgrounds by applying to the text analysis Edward Hall's division into high-context and low-context cultures and Geert Hofstede's cultural individualism-collectivism dimension in order to check if the autobiographies may serve as the exemplifications of Hall's and Hofstede's concepts.

\section{Close Encounters of Rutkiewicz and Blum}

The idea of comparing and contrasting these mountain-travel writings was drawn from the encounters of the two groundbreaking figures, described in both autobiographies. The dweller of Europe and the inhabitant of North America met for the first time in 1972, during their attempts to scale Noshaq, the second highest seven-thousander in the Hindu Kush Range in Afghanistan, when Rutkiewicz was a member of the Warsaw Alpine Club's expedition, and Blum was carrying out the Endless Winter, her project to reach high peaks on different continents. When the depictions of those encounters are under comparison, it is possible for the reader to notice that we learn much more about the circumstances of the meetings from Blum's Breaking Trail than from Rutkiewicz's very general comments. In Na jednej linie, in a short five-sentence paragraph, Rutkiewicz mentions that, apart from a Norwegian team and a commercial expedition led by Reinhold Messner, in base camp there was a group of American mountaineers traveling round the world with intent to scale selected peaks, which undoubtedly implies Blum's Endless Winter undertaking. In addition to concentrating her attention on their highly professional equipment and freeze-dried food, the products that, in fact, were missing in Blum and her co-travelers' provisions, Rutkiewicz reveals that the acclimatized Americans were able to begin the ascent immediately (Rutkiewicz and Matuszewska 2010, 94; Blum 2005, 141). Unfortunately, focused on establishing 
camps, the Polish team did not notice whether the American group had managed to summit Noshaq, and, according to Rutkiewicz, chanced upon the party only on their way back in the village of Quasi Deh (Rutkiewicz and Matuszewska 94). Moreover, Rutkiewicz evokes the memory of Arlene Blum by surname only once in her personal narrative, mentioning that during their meeting on the slopes of Noshaq they resolved to organize a Polish-American women's expedition to scale an eight-thousand-meter peak, which, in effect, never happened but, in Rutkiewicz's opinion, gave rise to the 1975 Polish Gasherbrum project co-led by the Polish mountaineer (Rutkiewicz and Matuszewska 103). It is worthwhile to note that Rutkiewicz calls out the name of Arlene Blum in the margins of her discussion on the independence of female climbers, such as Alison ChadwickOnyszkiewicz and Ewa Czarniecka-Marczak, who-although married-were capable of climbing individually doing technically difficult routes with no support from their spouses, an activity Rutkiewicz initially considered impossible.

Blum's account of the relationship between the two high-performance climbers is definitely more informative, providing us with details that help the reader to envision the events in which both of them participated. In Breaking Trail, with pinpoint accuracy, Blum recounts at least four encounters between the two cragswomen. The first meeting took place when Rutkiewicz approached the American team at Noshaq base camp to introduce herself (Blum, Breaking 143-44). Their second conversation that would later turn out to be an epochal event in the history of feminine mountaineering occurred when Rutkiewicz was descending the summit while Blum was attempting to ascend it. According to Blum, that was the moment when Rutkiewicz suggested the organization of an all-women expedition to an eight-thousander, the high-altitude plan put into effect only by men at that time: "We women climbed to 7,500 meters ... Now we go to 8,000 meters, all women [sic]" (Rutkiewicz qtd. in Blum, Breaking 146). The thought buzzing in Blum's head when she was trudging upward was also the topic of the climbers' subsequent conversation during an international social gathering at base camp, when together with Chadwick-Onyszkiewicz, they considered real possibilities of putting into action the idea initially produced by Rutkiewicz (Blum, Breaking 147-48). In other words, the Polish team, still being at Noshaq base camp, must have found out whether the Americans had topped the summit or not. And certainly, they must have had other occasions to talk if both parties co-existed at Noshaq base camp for approximately six weeks 
(Blum, "Re:Question"), although neither of the writers records this fact in their works. In Blum's autobiography there is additionally a mention of the three women's correspondence devoted to their ambitious plan, omitted in Rutkiewicz's Na jednej linie (Blum, Breaking 151). Furthermore, in Breaking Trail Blum refers to another reunion with the Polish mountaineer at Peak Lenin base camp, where Rutkiewicz had flown by helicopter to resume the discussion on their project to organize a women's expedition to an eight-thousand-meter peak (Blum, Breaking 181-82). And admittedly, Rutkiewicz touches upon the visit paid to the camp on her way from the hospital to the Korzhenevskaya Peak encampment. Nevertheless, the fact remains that in her narrative there is only an allusion to the Americans' presence on the slopes of the mountain when the author of $\mathrm{Na}$ jednej linie mainly focuses on the memorable 1974 Lenin Peak tragedy that took the lives of eight Russian women climbers (Rutkiewicz and Matuszewska 117), again detailed more precisely in Breaking Trail, together with other calamities happening there in the same season (Blum, Breaking $164,173,176-79)$.

\section{Na jednej linie and Breaking Trail as High-Context and Low- Context Cultures' Texts}

The apparent differences in describing the mountaineers' mutual encounters clearly illustrate diverse ways of communication characteristic of Edward Hall's widely-known division into highcontext and low-context cultures (Hall 114-15; Jandt 76). To thoroughly elaborate on Hall's theory is beyond the scope of this article, yet for the sake of the analysis it is necessary to give the fundamental points characterizing communication in both cultures, scrutinized by the author of Beyond Culture, who actually himself encourages the reader to search for examples in the field of literature (Hall 114). According to Hall, communication in low-context cultures epitomized by the United States is marked by direct messages, explicit comments, and elaborate instructions. In this type of culture, more knowledge is made public, and therefore it is more accessible for the receiver of a statement. In addition to well-developed argumentation and detailed descriptions, the logical organization of a text is expected, and the meaning of an encoded thought is openly displayed. In contrast, communication in high-context cultures exemplified by China, Japan, and the 1980s Poland is more layered and nuanced with more shades of meaning and expression. More 
information is implicit and internalized in a message-carrier who keeps knowledge below the waterline, and does not share with the receiver comprehensive information. As a result, the receiver of an encoded thought is obliged to read between the lines to decode a transmitted message that may lack details and, consequently, objectivity.

When Blum's and Rutkiewicz's works are juxtaposed, their autobiographies represent respectively the texts reflecting communication in low-context and high-context cultures. Although both authors put into words similarly sounding risky undertakings, and the activity in high-altitude mountains constitutes the leitmotif running through both autobiographies, their personal narratives differ in the style of writing and in structure. A representative of a low-context culture, Blum explicitly elaborates on her mountaineering experiences which, as she concedes in a 2010 New York Times article, constitute "Ninety-eight percent of the book" (qtd. in Dinkelspiel). Still, even if her autobiography is subtitled with the phrase "A Climbing Life," in the introduction the author additionally points out two other strands essential in her storyline: "short childhood vignettes" and "snapshots of ... [her] career as a scientist" (Blum, Breaking xiii). Nevertheless, it appears that Blum allows us the penetrating insight into various spheres of her existence: public, professional, private, and even intimate, relating "a compelling narrative on many levels" (Bonington ix). Going beyond the space of the mountains, she thus generously shares with the reader not only her memories regarding childhood, adolescence, college years, and her professional path to academic posts, but also the history of her relationships, openly discussing intimate situations, and the way to motherhood, her "life's favorite adventure" as she concludes in Breaking Trail (300). In Chris Bonington's view, Blum's autobiographical story is also "an important account of the development of women's climbing" at the time when female achievements were still largely denigrated (Bonington ix).

The structure of Breaking Trail also shows the in-depth analysis logically carried out in the process of writing and Blum's attention to detail, the features typical of the communication system in the low-context culture. In order to help the reading audience recognize the correlation between various events that have occurred during her lifetime, Blum divides each chapter into two sections: the aforementioned "childhood vignettes" and the longer stories of adulthood, titled, dated, and additionally distinguished by two different fonts. Thus, chapter four, for instance, touches upon the public denial to nurture her ambitions, initially in a Chicago local synagogue when, as an eleven- 
year-old girl, she was not allowed to read prayers, and then, as an MIT student, when she was denied the opportunity to join a Ph.D. research group just because of her sex (Blum, Breaking 2326). It is worthwhile to highlight that the former end when the latter begin, since the childhood scenes chronicle the early years of her life up to the moment when she was aged seventeen and left home to enter higher education at Reed College in August 1962 (Blum, Breaking 301), and the stories of adulthood open with her first escapade to high mountains, the 1964 attempt to top Mt. Adams in the Cascade Range, where she took the initial lesson on mountaineering.

Furthermore, highly specific and following the conventions of communication in low-context cultures, Blum makes every effort to present a precisely veritable and factual account. Therefore, she provides the reader with minute details where and when a particular event happened, who was involved in the situation, what feelings it, or them, aroused in her, and how the given occurrence influenced her mindset. As she asserts in the introduction to Breaking Trail, "Using my diaries, articles written following my trips, and my imperfect memory, I have tried to describe my experiences honestly and accurately. Whenever possible, I verified information with teammates, colleagues, and friends" (Blum, Breaking xiii). And indeed, in the acknowledgements, immensely grateful for the help of her writing mentor, Luree Miller (1926-1996), ${ }^{[2]}$ Blum lists numerous surnames of those that contributed to the publication of her personal narrative, registering not only those who commented on the manuscript, but also those that baked a "blackberry pie, an ingredient of inspiration" (Blum, Breaking 313). As seen in the autobiography written with a view to preserving objectivity, Blum, in the process of composition, listened to the tape recordings made during her mountain adventures (Blum, Breaking 213, 230). Additionally, in the chapters, it is possible to find fragments derived from the correspondence and diaries penned by other witnesses of a given occurrence, which are intertwined in her story especially when there is a description of an expedition's pivotal moment, a serious conflict, tension, or a climber's death (Blum, Breaking $119,150,181,190,213,223,228,232,249)$. Of great importance is also the fact that Breaking Trail constitutes a well-thought-out piece of photographic reportage, because each chapter is provided with a few photographs, mostly from Blum's collection, allowing us to conjure up the places the author has explored, to better imagine the situations in which she has found herself, and to have a closer look at the people she has encountered in her life. In a way, it is feasible for the 
reader to follow Blum's steps as the autobiography contains maps drawn by cartographers Stace Wright and Dee Molenaar, which visually display her mountaineering and trekking exploits (Blum, Breaking 311).

In contrast to the long list of contributors whose input Blum openly acknowledges, Rutkiewicz composed the autobiography whose authorship, for some writers, remains a contentious issue. In Wielka Encyklopedia Tatrzańska (The Great Encyclopedia of the Tatra Mountains), in the biographical entry on Wanda Rutkiewicz, it is stated that in her autobiography Na jednej linie "the narration was expressly distorted by another person's inappropriate intrusion" (Paryski and Radwańska-Paryska 1044). The comment appears to stem from Rutkiewicz's long-time cooperation and friendship with journalist and writer Ewa Matuszewska (1945-2018), a member of the climber's informal Warsaw "headquarters," who in the circle of close friends helping Rutkiewicz to organize expeditions was responsible for her public relations (Kamińska 325-26, 345). According to Anna Kamińska, the author of the 2017 biography of Wanda Rutkiewicz, after the successful ascent of Everest, Matuszewska befriended Rutkiewicz, and together they began to write books, i.e., Matuszewska recorded and put in writing the story spun by Rutkiewicz (Kamińska 345), as hinted in the autobiography's title page on which there is the information on the author's cooperation with her friend (Rutkiewicz and Matuszewska 3). In fact, Matuszewska's introduction to the 2010 edition of the book begins with the statement declaring that they both "started writing" a few months after the Everest exploit, nevertheless, she strongly denounces the indicated intrusion into Rutkiewicz's life-story (Matuszewska, "Powrót" 5). In her biography of the first woman on K2, Matuszewska also emphasizes that as far as $\mathrm{Na}$ jednej linie is concerned, Rutkiewicz "took great care to make sure it was her book," making a stand against the correction of some expressions that sounded awkward to Matuszewska, who finally gave up imposing her alterations, but, in fact, should be credited with titling the autobiography, the idea Rutkiewicz welcomed (Matuszewska, Uciec 67). Still, Kamińska concedes that at first Rutkiewicz authorized the texts recorded by Matuszewska, but later she did not even read them (Kamińska 345), since, as Matuszewska claims, Rutkiewcz had "neither patience nor time to write ... She rushed from expedition to expedition" (Matuszewska qtd. in Kamińska 357). 
Born and raised in a high-context culture, Rutkiewicz recounts her intriguing story in a more implicit manner than Blum, not communicating particulars about the selected occurrences revealed in the narrative. In contrast to Blum's account, Rutkiewicz's Na jednej linie concentrates on the first phase of her climbing life, spanning the adventures from 1961, the beginning of her mountain fascination in the Rudawy Janowickie (Rutkiewicz and Matuszewska 25; Kamińska 107), up to the 1978 successful ascent of Everest, her first eight-thousander, to which one-fifth of the book is devoted. Relating the early daring exploits in the Sudetes, Tatras, Alps, and in Norway, she also describes the failures of the challenging attempts, such as the ones on Korzhenevskaya Peak in 1974 and on Nanga Parbat in 1976. However, in her autobiography, Rutkiewicz does not discuss the postEverest period encompassing her most memorable undertakings, including the ascents of the other seven eight-thousand-meter peaks, the story continued by Matuszewska in Karawana do marzen (The Caravan to Dreams, 1994), the friend's tribute published two years after Rutkiewicz's death. Nor does she share with the reader the private side of her life, marginalizing the years before the first climb, which are summarized on the first two pages of the autobiography. Silent about personal relationships and friendships, she does not refer to her failed married life at all, whose trace is noticeable in the autobiography only in the enclosed official correspondence from the Warsaw Alpine Club to Wanda Błaszkiewicz-Rutkiewicz (Rutkiewicz and Matuszewska 71), of whom more information is revealed in Kamińska's well-researched biography. The controversial 1975 Gasherbrum expedition, a sports accomplishment yet a total failure in interpersonal communication, is subjectively reported from Rutkiewicz's point of view. Her statement is balanced when we hear the other team members' opinions, expressed very emotionally in the expeditionbased documentary Temperatura wrzenia (The Boiling Point, 1976), which, according to Rutkiewicz, presents only "the worse side of the story" (Rutkiewicz and Matuszewska 143). With over twenty photographs showing Rutkiewicz in different stages of her life, the autobiography creates the picture of a person who mainly lived for climbing and climbed to live, subordinating her thoughts and deeds to high-altitude mountaineering. Clearly, her narrative differs from Blum's story, yet when Rutkiewicz appears to be resistant to accept the others' versions of the past happening, the author of Breaking Trail allows dissenting voices to be heard: "our recollections are 
colored by our personal perspectives, and I recognize that others might have different memories of some of these events" (Blum, Breaking xiii).

\section{The Hofstede Dimension in the Autobiographies}

With references to other researchers, Young Yun Kim points to the correlation between Hall's concept of high-context and low-context communication systems and Geert Hofstede's individualism-collectivism dimension observable in cross-cultural communication (558). Again, to scrutinize thoroughly Hofstede's theory is beyond the scope of this article, however, to give the analysis the required background, one needs to list the characteristics of the cultures marked by individualism and collectivism. In a collectivist culture, the interest of a group obviously dominates the interest of an individual person, whereas in an individualist culture, self-achievement, selfassertion, and personal goals are preferably in focus. The former strongly accentuates the relationships with others and one's loyalty to them, while the latter minimalizes one's consideration given to a group (Jandt 168-69).

When we apply Hofstede's cultural individualism-collectivism dimension to the analysis, Poland - in the past a satellite country of the Soviet Union - epitomized a collectivist culture in the second half of the twentieth century, whereas the individualist United States is still categorized as a culture in which the interest of the individual has prevailed over the interest of a group, legally speaking, since the 1791 Bill of Rights. Nevertheless, when we scrutinize the autobiographies through the individualism-collectivism distinction that usually overlaps with Hall's concept, the authors' beliefs and decisions appear to advocate the classification contrary to the country of origin. Admittedly, Rutkiewicz claims that at the introductory stage where she was gaining mountaineering experience in Polish mountains and hills (in the early 1960s), "people were the most important" to her, together with climbing and nature (Rutkiewicz and Matuszewska 28). And later, when scaling the world's towering ranges, she usually appreciates precious hours spent in base camp, preferring solitude with a possibility of enjoying the company of other climbers. Yet, she does not regard an expedition team as a tightly-knit group whose common objective is "to kick a ball into the same goal" (Rutkiewicz and Matuszewska 87). And when Rutkiewicz comments on a successful high-altitude expedition, from her point of view, it is only partially just to present all group members with medals 
for a great sports achievement since the whole team worked on summiters' success only to a certain extent (Rutkiewicz and Matuszewska 70). Of crucial importance is also Rutkiewicz's differentiation between Polish and Russian alpinists, observed during her first high-mountain expeditions to Asia. According to Rutkiewicz, such issues as the brotherhood of the rope and heroism in the mountains were distinctive features of heroic climbing, a way of living mastered by Russian mountaineers. In regard to Polish rock climbers, Rutkiewicz concludes: "for us, individual experiences were the most important. We aimed to enrich personality, not to test it," being accustomed to independent activity in the mountains rather than to mass climbing (Rutkiewicz and Matuszewska 77-79). Moreover, playing the role of a pioneer in the field of mountaineering, as well as the achievement of success, appears to her to be of great value, as she emphasizes the surnames of the climbers who have been the first on the top of a mountain, also feeling envious of Zofia Szajuk (1940-1988), the first Polish woman that had climbed above 7000 meters, and of her accomplishment of reaching Lenin Peak (Paryski and Radwańska-Paryska 1178; Rutkiewicz and Matuszewska 78). In addition to stressing the importance of self-reliance, Rutkiewicz admired Reinhold Messner, not only for being the first to climb all fourteen eight-thousanders, but also for his ability to generate widespread publicity, since she believed that "something more is needed than technique and physical condition in order to create a legend around one's person" (Rutkiewicz and Matuszewska 94).

By curious paradox, a citizen of the individualist United States, Blum appears to have a collectivist attitude to mountaineering. In disagreement with the head of the 1970 historic Denali expedition, Blum, a deputy leader, emphasizes that "[s]taying a cohesive team mattered to me as much as climbing the mountain" (Blum, Breaking 76). Cognizant of problematic group dynamics that might surface during high-altitude climbing, Blum, before leaving the United States, resolved to arrange a meeting with a psychologist to eschew possible miscommunication in Nepal in spite of the group's skepticism (Blum, Breaking 220). Hence, as David Mazel notes, the memorable 1978 Annapurna project meant "to conspicuously repudiate the patriarchal model in favor of the sort of egalitarian communalism" (18), although Blum's intentions to opt for the interest of the whole group rather than for individual choices were not always sufficient for avoiding some divisions in the team (Rak 131). It is worthwhile to mention that as a leader she gave up summiting the eight-thousand-meter 
Himalayan giant and focused on leading the expedition whereas Rutkiewicz "led and climbed" (McDonald 44). In the face of constantly falling avalanches, Blum even questioned the idea of organizing a Himalayan expedition (Blum, Breaking 250), the decision that Rutkiewicz hardly ever had doubts about.

Furthermore, in Blum's depictions of the climbs and treks in which she has participated, there is a recurrent need to forge bonds with the Levinasian Other, which is possible for the reader to observe by the author's preference to employ such words as family and friends. During the 1974 Pamir International Alpine Camp held by the Soviet Sports Foundation, when experiencing the tragedies on Lenin Peak, the American mountaineer reveals that she "felt part of a caring international family of climbers" (Blum, Breaking 176), and when describing the membership of the memorable Annapurna expedition, she also characterizes the team as "this family of women, a family with whom I would struggle, celebrate, and mourn" (Blum, Breaking 217). Despite a deeply felt personal miscommunication with her co-traveler during a several-month trek, Blum captions the photograph presenting herself, Hugh Swift, and porters as "The Great Himalayan Traverse family," accentuating that she needed "a friend with whom to talk and share our adventure" while her companion relished the hike "in his own private way" (Blum, Breaking 270-71). And that seems to have been Blum's fundamental need since the moment when she was tied to the rope for the first time, as she, probably partially, jokes about her first mountaineering experience, when roped up between two young male climbers: "I liked the secure feeling of this umbilical cord connecting me to these strong, attractive guys" (Blum, Breaking 2).

Individualist cultures are marked by competitiveness and confrontation, nevertheless, these are the features cherished not so much by the American cragswoman as by the Polish climber brought up in the atmosphere of collectivism. "[A] competitor by nature," as she spoke of herself (Rutkiewicz qtd. in Reinisch 30), Rutkiewicz treats mountains and other climbers as opponents that must be challenged. In the narration of the 1966 climb along the Mont Blanc ridge, Rutkiewicz admits she felt happiness when, together with her rope partner, Elżbieta Miszczak-Piekarczyk, she had managed to leave others behind (Rutkiewicz and Matuszewska 51). On the other hand, she cries, venting anger when an expedition to the Turkestan Range failed to top Szczurowski Peak (Rutkiewicz and Matuszewska 76; Kiełkowski 709). Assessing team members' chances to scale 
Everest, she touches upon readiness "to fight not only with the mountains but also with the people standing in would-be summiters' way," the people that in one fragment she calls "enemies" (Rutkiewicz and Matuszewska 172, 178). The attempt on the world's highest peak appears to be part of a boxing or wrestling match, since the safe descent from Camp II to Camp I is regarded by Rutkiewicz as "the round" she has won when struggling with Everest (Rutkiewicz and Matuszewska 169, 174). Leading Poland's first women climbers' expedition, yet combined, in fact, with the men's team (Reinisch 32, 35), she applied "a war strategy" to reach the then unclimbed Gasherbrum III, the tactic that resulted in a success with a bitter-and-sweet taste due to deep misunderstanding in the group (Rutkiewicz and Matuszewska 137). One of the "conquerors" celebrating "a victory" on top of Everest and leaving there the trace of her presence ${ }^{[3]}$ (Rutkiewicz and Matuszewska 191, 199-200), Rutkiewicz thus wrote a story that bears similarity to numerous climbing accounts narrated in military terms since the first successful attempt on Mount Blanc in 1786 (Roberts 37; Hansen 9), which presents her as the victor of the struggle fought with mountains and men. Still, it should be stressed that standing on the very top of the world makes her humble and grateful for the personal achievement, and she does not raise her hands in a triumphant gesture, as Maurice Herzog did in 1950 when summiting the first eight-thousand-meter peak in Himalayan climbing history.

Born, raised, and educated in an individualist culture, Arlene Blum is rather reluctant to play the role of the conqueror both in Breaking Trail and in the travelogue that preceded it. The author meaningfully opens up her Annapurna autobiography with such a statement: "You never conquer a mountain. / You stand on the summit a few moments, / Then the wind blows your footprints away" (Blum, Annapurna vii), which is also the belief interwoven into the later published narrative about her climbing life. Saying farewell to Sagarmatha, a Nepali name for Everest, which for her has remained unclimbed, she was aware that the snowfall and blowing wind would erase her presence on its slopes, "and there would be no trace of our ever having been on Mt. Everest" (Blum, Breaking 211). In further contrast to Rutkiewicz, Blum does not seem to be driven by the urge to reach the top of a high-altitude peak, more easily giving up the idea of summiting than the Polish climber if conditions are not favorable. Appreciating natural landscape, Blum relishes "a feast of mountains" in the Kishtwar Himalaya, in northern India, with no "appetite or the utensils for the 
meal" (Blum, Breaking 135-36). As the leader of the Annapurna expedition, she cries releasing cumulative emotions, feeling relief that the four members of the team have finally reached the top not because of her failure to reach the summit (Blum, Breaking 233). Yet, that does not mean Blum lacks determination to climb. On the contrary, "[e]very summit was a miracle" to the entrant of the art of mountaineering, and as "the Queen of Tenacity," the nickname coined by a male co-traveler, she continued the arduous ascent of Shiva, in the Jammu and Kashmir region, inching higher and higher when her male co-climbers clearly intended to go down. Unlike Rutkiewicz, Blum, however, gives the reader the impression that her aim is not to conquer, but rather to break trail literally and figuratively in the uncharted territory. During her attempt on over seven-thousand-meter Noshaq, ultimately left unclimbed by the American mountaineer, she deliberates on her presence in the high-altitude mountains: "Each step took me higher than I'd ever been and I longed to explore the unknown physical and psychological terrain that lay above" (Blum, Breaking 146).

\section{Mountains as Seen by Rutkiewicz and Blum}

Displaying emotions and adopting a particular attitude, Rutkiewicz's mountains seem to have personality. As she writes in her autobiography, Everest is patient to her, full of acceptance, as it has allowed the climbers to reach its top, to be victorious, although she has not reciprocated the feelings treating "her opponent with no warm feelings for its beauty and power" (Rutkiewicz and Matuszewska 200). Infamous for the high death toll, Nanga Parbat, an eight-thousand-meter peak in the Pakistani Himalaya, is called by Rutkiewicz "the cursed mountain," the significant phrase that serves as the title for one of the autobiography's chapters, dedicated to the 1976 international expedition abandoned owing to Sebastian Arnold's fatal fall. The steep slopes surrounding Rutkiewicz sometimes make her trapped and claustrophobic by blocking the way, which evokes in the mountaineer the feeling of dislike, or even vengeance against nature: "I don't like them. They'll pay for that later" (Rutkiewicz and Matuszewska 107). In addition to playing unfair by sending atrocious weather, Rutkiewicz's mountains may accept the challenge posed by potential conquerors capable of "tam[ing]" the giant they wish to top (Rutkiewicz and Matuszewska 135, 173). Clearly, fraught with peril, they are likely to be the source of stress and of threat, and therefore one may trek and climb on condition that they have the certainty that "they will cope with 
mountains" (Rutkiewicz and Matuszewska 173; emphasis added), as if it were possible to achieve an illusory mastery over nature.

Similar to Edward Abbey's desert being indifferent to the presence of the human self (Abbey 334), Blum's mountains are rather the landscape that helps her restore her inner balance despite the self-imposed exposition to ever-present hazards at high altitude. In Breaking Trail there is a recurrent scene in which the climber's mind regains serenity when she trudges up a mountain with a massive load. For instance, in one of the fragments on the Denali climb the writer contemplates:

Climbing the ridge was an extreme meditation, thinking about my breathing and moving with focus, concentration, and harmony. Where I placed my foot determined whether I lived or died. Future plans, past regrets, and the formal clutter of my mind were silenced. I felt a sense of peace and distance from the world reminiscent of that I'd found as a child up in our cherry tree or in the vacant lot watching the clouds (Blum, Breaking 74).

Put differently, instead of competing on and with steep slopes, Blum goes into competition with herself, the chaos in her head, false perceptions and misconceptions, challenging her inner world rather than the outdoor environment. By continuing step by step up the mountain slope, she delves deep into her inner self, attempting to understand her personal problems, sorrows, deliberating on upcoming events in her life, and bearing in mind the thin line between life and death. Obviously, Rutkiewicz must also have been preoccupied with such thoughts, yet the distinction between these two climbing icons is that Blum shares her line of thinking with the reader in numerous fragments, treating mountains as a helpful medium for restoring her inner equilibrium (Blum, Breaking 112, $150,189)$. Hence, she does not epitomize soaring peaks as adversaries, or build a love-hate relationship with nature that in her case seems to serve primarily as a platform for personal development, the space where, first and foremost, she is able to redirect her reasoning, silence emotions, and finally return to herself. A constant reminder of the fragility of human existence, Blum's mountains are additionally a source of inspiration to the scientist searching for answers to bothering questions. Through the close observation of the glacier on Lenin Peak, in the Kyrgyzstan-Tajikistan borderlands, the climbing researcher came up with a solution to the perplexing chemistry puzzle she had been trying to solve in the flatlands (Blum, Breaking 185). Thus, Blum's mountains also act as a springboard for academic development, stimulating the 
advancement of knowledge. As Stanford and Paris-based biochemists assert, the experiment envisioned when watching the slopes of the seven-thousander turned out to be "groundbreaking" and "initiated a very productive ... area of research" (qtd. in Blum, Breaking 185).

\section{Conclusion}

Although both authors put into words the thought-provoking stories of their on-the-edge lives, Rutkiewicz and Blum wrote different autobiographies. A representative of the low-context culture, the American climber penned the highly detailed and elaborate account of her mountaineering experiences as well as other life adventures, which she verified with a large number of contributors in order to preserve as much objectivity as possible. In cooperation with co-author Matuszewska, Rutkiewicz, principally focused on her mountaineering activity and marginalized other spheres of life, which she depicted in a more general manner than Blum, omitting some particulars revealed in Breaking Trail. Thus, it may be concluded that the climbers' autobiographies quite faithfully exemplify two different ways of communication characteristic of high-context and low-context cultures that Rutkiewicz and Blum represent respectively. Nevertheless, if we apply Hofstede's cultural individualism-collectivism dimension to both texts, it is possible to infer that the autobiographies' content usually contradicts the cultural values dominant in the nonconformist United States and in the group-oriented Poland of the second half of the twentieth century. Raised in the collectivist culture, Rutkiewicz holds in high regard individual achievement, independent activity, self-reliance, and competitiveness, leading the group to the top of a mountain. Blum attaches the most importance to a cohesive team and prioritizes the interest of the climbing family, aiming to hold the group together. In other words, although Hall's concept and Hofstede's dimension tend to overlap as instructed in cross-cultural academic textbooks, the scrutinized autobiographies clearly show that literature may not provide required exemplification yet prove the opposite, offering instead true-to-life stories, especially if the two selected narratives were penned by the women who cannot be treated as a Jane Q. Public, since they both changed the chapters of Himalayan climbing's history by paving the way for future female mountaineers following their steps. 


\section{Works Cited}

Abbey, Edward. Desert Solitaire. Ballantine Books, 1990.

Blum, Arlene. Annapurna: A Woman's Place. Sierra Club Books, 1998.

Blum, Arlene. Breaking Trail: A Climbing Life. Scribner, 2005.

Blum, Arlene. "Re: Question Regarding Wanda Rutkiewicz.' Received by Agnieszka Kaczmarek, 3 Sept. 2018.

Bonington, Chris. Foreword. Breaking Trail: A Climbing Life, by A. Blum, Scribner, 2005, pp. ix-x.

Dinkelspiel, Frances. "Working It Out Through Walking." The New York Times, 15 May 2010, www.nytimes.com/2010/05/16/us/16sfvistas.html. Accessed 4 May 2018.

Hall, Edward T. Beyond Culture. Doubleday, 1989.

Hansen, Peter H. The Summits of Modern Man. Harvard University Press, 2013.

Jandt, Fred E. An Introduction to Intercultural Communication. SAGE Publications, 2018.

Kamińska, Anna. Wanda. Opowieść o sile życia i śmierci [Wanda: A Story About the Power of Life and Death]. Wydawnictwo Literackie, 2017.

Kiełkowski, Jan. "Szczurowskiego, Pik." Wielka encyklopedia gór i alpinizmu. Góry Azji [The Great Encyclopedia of Mountains and Alpinism: The Mountains of Asia], edited by Małgorzata Kiełkowska and Jan Kiełkowski, Stapis, 2005, p. 709.

Kim, Young Yun. "Inquiry in Intercultural and Development Communication." Journal of Communication, vol. 55, no. 3, 2005, pp. 554-77.

Matuszewska, Ewa. Uciec jak najwyżej: nie dokończone życie Wandy Rutkiewicz [Escaping to the Highest: The Unfinished Life of Wanda Rutkiewicz]. Iskry, 2007.

Matuszewska, Ewa. "Powrót do czasu zaprzeszłego" ["Return to the Past"]. Na jednej linie [On One Rope], by Wanda Rutkiewicz and Ewa Matuszewska, Iskry, 2010, p. 5.

Mazel, David. Introduction. Mountaineering Women: Stories by Early Climbers, edited by David Mazel, Texas A\&M University Press, 1994, pp. 3-26. 
McDonald, Bernadette. Freedom Climbers. Vertebrate Publishing, 2012.

Paryski, Witold, and Zofia Radwańska-Paryska. Wielka Encyklopedia Tatrzańska [The Great Encyclopedia of the Tatra Mountains]. Wydawnictwo Górskie, 1995.

Rak, Julie. "Social Climbing on Annapurna: Gender in High-altitude Mountaineering Narratives." English Studies in Canada, vol. 33, no. 1/2, 2007, pp. 109-46, web-1b-1ebscohost-1com10000f47p001b.han.uni.opole.pl/ehost/pdfviewer/pdfviewer?vid=3\&sid=295851fb-47b0-41278e3d-f9bac9ee2b2c\%40pdc-v-sessmgr02. Accessed 20 July 2017.

Reinisch, Gertrude. Wanda Rutkiewicz: A Caravan of Dreams. Translated by Dieter Pevsner, Carreg Ltd., 2000.

Roberts, David. True Summit. Simon \& Schuster, 2000.

Rutkiewicz, Wanda, and Ewa Matuszewska. Na jednej linie [On One Rope]. Iskry, 2010.

Temperatura wrzenia [The Boiling Point]. Directed by Andrzej Zajączkowski, Telewizja Polska, 1976. 
[1] The authorship of $\mathrm{Na}$ jednej linie is discussed later in the article, however, to emphasize Matuszewska's contribution to its publication, the author of the article gives both surnames, Rutkiewicz and Matuszewska, in bracket references and in the list of cited works. All in-text citations derived from Polish books are translated by the author.

[2] Luree Miller authored, among other things, On Top of the World: Five Women Explorers in Tibet (1984), devoted to the exploits of Nina Mazuchelli, Annie Taylor, Isabella Bird Bishop, Fanny Bullock Workman, and Alexandra David-Neel.

[3] In Na jednej linie, Rutkiewicz mentions that on top of Everest she left "the symbol of friendship," a little stone received from climber Irena Kęsa (Rutkiewicz and Matuszewska 200), which features Rutkiewicz's loyalty to the Other to a certain degree.

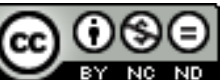

Creative Commons Attribution-NonCommercial-NoDerivatives 4.0 International License 